\title{
The Esloo design for the digital elementary and secondary education
}

\author{
Jaap Westbroek \\ School Group Esloo, Rijnlandlaan 1,2273 CT Voorburg. \\ Esloo@svm.nl
}

\begin{abstract}
In the Netherlands near The Hague Schoolgroup Esloo will build a future school for prevocational education, with a focus on the technical vocations. It will be made with the people of the old school that is part of the Schoolgroup. The school will be named Corbulo College. Corbulo was a Roman soldier who built a village in the $1^{\mathrm{e}}$ century. The school will be opened in august 2001. In this article we will introduce the way this design was developed for a future school and the way we the design is implemented. We will accentuate the role of architecture and the role of ICT. Over the next few years, there will be substantial investment in the use of ICT and in the connection to internet in Dutch schools within the major programmes of the Dutch government. They are called "Investing in Progress" and "Education online" and Schoolgroup Esloo is one of the front schools for implementation.
\end{abstract}

Keywords: Ethics, building design, creativity, curriculum development, pedagogy

\section{INTRODUCTION}

To think about the future is only possible when it will take place on different levels. This means two things: we have to put the school in a sociological and historical context and we have to make philosophy part of the thinking process. Especially in times of great change we have to analyse the base of the change and when you want to do that in a profound way you get to philosophy.

Not only for analysing we used philosophy. When we want to make a demo of the future, it is not enough to describe the concrete situation we

The original version of this chapter was revised: The copyright line was incorrect. This has been corrected. The Erratum to this chapter is available at DOI: 10.1007/978-0-387-35403-3_29 
want to create. The starting school is part of a dynamic process so we have to consider the concrete situation in its historical perspective. Describing it on a philosophical level will make clear in which direction the process will continue.

This paper will elaborate on the way we think about education. Education has an ethical and a social aspect. It has to give our youth the possibilities to become citizens who are able to do their work in society. But they also have to be good citizens who are constantly asking questions to society about the developments going on. So education has to give the tool to the youth to ask the good questions as well. That is the ethical task of education. In the whole of history you can see that there is a contrast between the education to be a normal citizen and the education to be a good citizen. Being good means being abnormal as well. So education has to give way to both. The starting-point of this paper is that the paradigms of future society based on a richness never achieved before will give citizens more possibilities to be abnormal, creative, etc. So that the contrast between the normal and the good will diminish in the future.

In "The disciplined mind" (1999) Howard Gardner says: "I believe that three very important concerns should animate education; these concerns have names and histories that extend far back into the past. There is a realm of truth - and its underside, what is false or indeterminable. There is the realm of beauty - and its absence in experiences or objects that are ugly or kitschy. And there is the realm of morality - what we consider to be good, and what we consider to be evil." To realise this, education has to change a lot. This paper wants to give an impression how it may be possible. Our school wants to become an example of that.

\section{MISSION}

Esloo operates on the following educational principles:

- education must be made-to-measure;

- education is demand-driven;

- education must take place in a small-scale environment;

- education provides the culture exchange that students need to shape their future;

- education advances self-reliance;

- education links up with the social environment. 


\section{TRANSITION TO AN INFORMATION SOCIETY}

"If knowledge is the centre of new society... It means that education is the leading branch of economy. How can we rethink that?

George Copa

These words say in a nutshell what Schoolgroup Esloo eventually wants to achieve through education. George Copa is a professor of Teaching and Learning of the University of Minnesota and one of the partners in thinking about both the shape and contents of the new school.

\subsection{Transitional period}

Maybe it has everything to do with the fin-de-siècle sentiment, but it is a fact that a lot of attention was given in the past to the mapping of the social changes brought to us by the $21^{\text {st }}$ century. To be able to build a school for the $21^{\text {st }}$ century, we first must have a clear picture of the changes society has been going through lately. These changes are described in many ways. They are sometimes referred to as the $3^{\text {rd }}$ Wave Society (Toffler, 1980), the information society or the demand-driven society.

Fast economic growth in East Asia, globalisation of the economy, the world becoming smaller because of the Internet, the shift from an industrial economy to an information society with a "new economy" seems to be decisive. The share of the service enterprises in the western economy has been growing increasingly for the past few years.

Creativity, intelligent products, integration of production and service have become the new fashion. In trade and industry people refer to learning organisations, intelligent enterprises and paradigm shifts as mental model for the future.

Generally speaking we live in a transitional period: the industrial society is nearing its end and the information society has already begun. Knowledge is the core of the information society. New concepts are promoted and life long learning is one of them. Trade unions and employers reach agreements on employability and flexibility. ICT becomes more and more basic to our society. We live in a dynamic society in which not only the changes develop more rapidly, but also the concepts that are fundamental to these changes. To Esloo it meant that building a new school could no longer be undertaken starting from concepts from the past.

Developing a concept for a new school then became a quest. Wherever it was possible we included outsiders in the project and we consulted the available literature. We noticed that especially in the management literature many interesting points were to be found. For example the metaphors that 
map the social changes have been developed there. Applying these metaphors to education bring along the changes of perceiving knowledge as economic capital only. Describing the school as an enterprise could imply that the relation between education and fundamental questions is abandoned. On our quest we encountered the contrary. The metaphors of the management literature that describe enterprises on their way to the information society refer to a society and to organisations which have been able to realise the targets and propositions we formulated for our school too. In the future information society knowledge will not only be referred to as economic capital but also as social and cultural capital. It means that truth, beauty and morality will be part of this conception of knowledge. Enterprises are willing to play a different role in information society.

\subsection{Life long learning}

All this rotates around knowledge, around the part of the creative human being in the production process, around the service and the entrepreneurial capacities expected from everyone, around flexibility and employability. The early industrial society made a clear distinction between education and labour. Education was reserved to young people who were shaped into cultural and social beings with the aid of education. The labour period followed the learning one. The earlier someone switched to the labour process, the lower his position on the social ladder would be. Since the quality of labour wasn't exactly high, it was better for children to stay away from it as long as possible. Hence we may declare the fights against child labour in favour of obligatory education with the logical consequence that neither working nor learning was fun.

The organisation of society based on this paradigm has been broken open in two ways since the fifties. First of all the dynamics of society led to the development of a totally different perception of the relation between labour and learning in adult life. This caused education to spread over the entire life span (life long learning). Secondly young people became more important economically; first as consumers, but later also as producers. Both developments made the principles of elementary and secondary education more and more contradictory to social reality. Students with lower levels of education, to whom education has less to offer, experience this even more strongly. So instead of referring to the division of life in consecutive learning, working and resting periods we refer to life long learning, working and, as a third item, personal development can be added. 


\subsection{Learning in the information society}

Until now in general secondary education there is not really a relation between learning and working. This means that elementary and secondary education lacks the potency of life long learning by which it is excluded of contributing substantially to shaping the $21^{\text {st }}$ century in which society will function on a much higher level. The principles of the information society oblige education to connect more to real life in stimulating young people more in their economic roles. Life long learning and life long working must be linked. Life long learning teaches people to get grip on their personal development through strategic knowledge and skills. This applies to both their producer and consumer role.

In the process of life long learning, learning can be reduced to only three strongly related learning areas: the own mind, the own body and the own environment. One spends a lifetime getting to terms with these three areas. This has to do with the three realms pointed by Howard Garner: the realm of truth, beauty and good. The acquired knowledge is put to use (= working) in the social and thus cultural context within which one operates. Meanwhile every culture of all times has always been permeated by this, it won't be until the information society, that the use of this knowledge will be given a full social implementation.

So we can see learning as a divergent and a convergent process. When a child is born it is seeking its way through the surrounding world and it is learning all the time and the surrounding world is growing during his whole life. This is the divergent process. But in puberty the identity of the adolescent makes his learning position convergent. He wants to know his own position in the environment. What will he do, who will he be, etc. The link between learning and working is a good metaphor for describing this converging process. It means that prevocational education can be the bridge and must be introduced in all forms of secondary education. As result education can address fundamental questions in an entirely new way. Not surprisingly this has strong effects on the learning contents, learning processes and learning environment. It gives content to the constructivist paradigm.

By all this education will be brought into the centre of society. It will develop new models for learning of which eventually enterprises and other social organisations will benefit. Herewith education plays the crucial part, which it is expected to play in a knowledge society.

Enterprises and schools will support the importance of the concepts of learning organisations and they will describe which qualities are needed. Hereby the role of general and purely factual knowledge strongly decreases, while the importance of metacognitive abilities, of development of other 
forms of intelligence, and of the management of abilities that belong to a learning organisation strongly increase.

It is necessary from both a social and economic point of view that these transformation processes do not intensify social splitting but strengthen unity. The creative capacity of the entire world population should contribute to the shaping of the $21^{\text {st }}$ century society. A real transformation of society can only take place if the changes in education regard all students.

\section{INNOVATION IN EDUCATIONAL PERSPECTIVE}

The innovations of education that are in accordance with the changes in society can be classed as follows:

1. the change of the curriculum;

2. the change of the role of both the teacher and student;

3. the change of the organisation;

4. the change of the physical learning environment.

These four classes are closely related: one change can't take place without the other. Our school is active in all classes. This is an important point because most of the rethinking of education until now is about the creation of a new didactical situation. In our vision this concerns only the second subject. Real change can not occur without redefining the other subjects as well.

\subsection{Curriculum}

We call the core of this transformation "context-oriented education". A "learning route" shapes life long learning educationally. Through such a route a student is prepared for his future. It describes a process from today to the future. For every student the learning route is divided in learning paths and the learning route co-ordinates the learning paths of students with the same future. For secondary education students, this future can either be the labour market or prolonged education. The learning route is a description that makes the consecutive situation the starting point of education. The notion "learning route" assumes a dynamic and future oriented culture exchange. The student always is the starting point of education. The cultural context of a student is dominant in composing the learning contents. Life long working is an integrated part of this culture. The educational learning situation is not anymore an isolated environment with no relation to real life, but exactly a situation that forms part of real life.

The curriculum is based on contexts of which the origin lies in real life. Within these contexts a broad range of skills is necessary to get to grips with 
the future. Not only cognitive skills are the issue here, but certainly also the development of reflective and emotional intelligence. With that education gains a much more strategic value by which it functions as a crowbar to make way to the future. Especially fundamental questions like the ones described by Howard Gardner as mentioned before can be brought under discussion in these contexts, and so context-oriented education does not only teach "how to learn" and "how to do" but also "how to live together" and "how to be" (Delors, 1996).

The thought structures of the general subjects are the basis of the contents. In the current educational organisation and examination programme these general subjects do not build a strong learning environment, because the contents do not relate to the demands of education, but mainly to reproduction. Therefore these general subjects do not really contribute to the raise of the educational level. The emphasis is put on the acquisition of declarative knowledge (facts) in the majority of the cases in stead of on the acquisition of the thought structures and of the interpretation framework with which the facts can be analysed. But the thought structures of the different subjects are the most important to learn. They form the cultural and historical basis of society. They give us the different ways in which we are able to look at and act in the world.

So in this new education we will finish with the dividing learning in the different subjects, a way of thinking that started after Renaissance. We integrate them in the contexts we mentioned. During the first two to three years of secondary education we use at school the program "City Works", from Boston. "City works" supplies the contexts within which the core targets of the fifteen obligatory subjects in secondary school can be combined. The three learning areas for context-oriented education are the mind, the body, and the environment, and they are given their completion in "City Works". Contacts with art and sport institutes etc. supply the contexts. It is the metaphor for the surrounding world.

The vocationally oriented subjects ${ }^{2}$ form the logic sequels for the contexts of the higher levels of secondary education. They build a strong learning environment by connecting life long working to life long learning.

${ }^{2}$ Traditionally a lot of attention is given to the vocationally oriented subjects in the Dutch lower training levels of secondary school. In the transition from 'City Works' to the real vocational education after secondary school, these subjects build an excellent basis for students to support their choice for a vocational training. The four professional categories for which the students can opt are technology, service, economy, and agriculture. Each context teaches the student to discover and develop his own qualities and wishes. Agriculture is seen as an environmental education; economy as the education how to be; service is the education how to live together, while technology shows the material standard of society. 
They will be able to teach productive knowledge that can be used in real life. Within the context of the vocationally oriented subjects, with their strong learning environment, and their orientation on teaching productive knowledge, the thought structures of the general education subjects are thought to raise the general level of education. The demands of the general subjects should therefore be limited to learning the thought structures relevant tot the subject. They give the real tools to handle real life problems. The factual knowledge does not belong in the examination program and will be liable to change in the curriculum depending on the contexts being offered.

\subsection{The role of teachers and students}

To the teacher this change means a change of role. He won't be a "knowit-all" any longer. To the contrary even: very often the students know more about dynamic developments than the teachers will do. Many students for instance have skills the teacher does not have. The most important role of the teacher is the role of coach in the learning process. Thus his pedagogic role is given a new content. The learning organisation will change as well. The class will be broken up into teams of for example seven students, and one teacher supervises seven of these teams. The breaking up of the class unit means that the discipline paradigm will be transformed. Consider that the teacher is playing his pedagogic part in the much more small-scale environment of seven students, either of one team or of the seven representatives of each team, while the other students work on their own. This brings forward the possibility to reinstall the master-apprentice relation, which is impossible in a class of thirty students.

This means a change in the role of the students as well. The students have to loose their reproductive role and will have a productive role mastering in a team their own learning process. Consider also the possibility that it is very easy to have tutors, composed of senior students, joining the small-scale unit. These senior students learn to make, as they tutor, their knowledge productive. Besides, the younger students are given positive role models that are more close to their own cultural environment. This means that working and learning go together here as well and that learning to communicate knowledge, essential to everyone in a knowledge society, is acquired during the tutoring. Besides, students learn to co-operate as a team, just as in real life. This new form of learning relations gives a view to many other changes. The tutorial situation doesn't stop at the frontiers of the school. On the contrary, it links the different parts of the learning community together. And it even links learning and working. Next to that it gives another change necessary in knowledge society. Kuhn (1996) described the 
present situation of schooling. He says that teachers are always teaching the paradigms that they studied themselves at the university. It means that our youth at school is structurally confronted with the knowledge of the past in stead of the present. In knowledge society it has to change. The structural integration of tutor systems in the learning environment can be an important step to leave the dilemma.

\subsection{The organisation}

The change in the role of teachers and students is described as a change in the organisation as well. We want to transform into a network organisation and we think about it as a fractal or Matrushka organisation, as we call it. But you can also define it in a more detailed way in biological terms describing the relation between different organisational levels. The work of Maturana and Varela (1980) about autopoiesis can be used in this way. It means that the change of class organisation proliferates through the entire school organisation in which for instance teams of seven teachers are made responsible for the education of about 200 students. And this will go on until the management of the school. The entire school organisation becomes an example of a network organisation and we can even introduce it in the way we work together with exterior organisations. It may be evident that this effects the occupational profile of the teacher and the manager. Their roles will not differ from each other so much. They have all a primary responsibility, a co-responsibility in the team in which they are a member and an end responsibility for the team they have to lead. The difference is set in the subject of responsibility. In the training plan of Esloo is established that in the development of the pedagogic qualities of the teacher and the manager attention should be paid to the teacher in his role of curious creator, inspirator, team player, coach, learner, planner, designer, entrepreneur, innovator, and ICT technologist.

\subsection{The architecture of the building}

All these changes can be expressed only if the physical learning environment, the school building, fits the task. The design of a new building will have to process all these new concepts. New construction on the basis of pedagogic and educational concepts is an enormous challenge. By preparing for the actual educational insights and anticipating the social developments, the new school will be an example in the almost unexplored field of educational innovation.

A school is built to be used last at least for 30 years. Thus, the new Esloo building will still have to meet the requirements of the year 2030. In 
translating the sketched developments into clear targets for the new school, we deal with a momentary impression. Therefore flexibility is essential to the plan. Insights of today can be old-fashioned tomorrow and it is by all means important to keep that in mind. Will the school in 2030 resemble the current school? Will there still be a bell ringing to announce the next hour? Will there be any breaks? Maybe not, since the students determine their own study program and their own breaks. Anyway, the school will become a place where there is room for the unexpected, for the unpredictable. This will finish the school built on the Napoleonic army barracks design with classrooms for 30 students next to each other. The concept of the classroom as an instruction locality with the teacher as the commanding officer and the schoolbook as the handbook for soldiers has finished. The school can't be built anymore on this concept in which external discipline equals learning, where there is no room for curiosity and where the unexpected and the unpredictable are not allowed.

When working and learning will be bridged the relation with the environment also must be redefined. Often secondary schools were built with a big gate all around the building like a prison and put in the middle of nowhere, so that the direct environment has no nuisance of the huge amount of adolescents. This has to change in the future as well. Older people have to come in the school for their life long learning process while our adolescents have to leave the school to work partially and learn in real life. So the gates must disappear and the school must become a learning centre in the middle of the community for example as part of a shopping centre, virtually linked to each other as virtual communities.

So the new building of our school is constructed as follows. At first it will be built on the place of the former school, that is happily for us next to a shopping centre, a two-floor building. It has a basic plan in the form of a $U$ on the ground floor and on the first floor but the first floor has the U-form upside down. The front of the ground floor is twice as high and marks the place for festivities, the forum. At the back of the building there is an opening in the ground floor because of the $U$ form while the opening in the $\mathrm{U}$ form of the first floor is filled by the height of the forum. The problem of security, important for the employees of the school, is solved: though there is no gate around the school, it will be possible to close the $U$ at the back.

As said, the place of the school makes it possible to be part of a shopping centre, in order to connect the school with a real life situation of working. We organised it on the ground floor. The glass front of the school with the room for festivities can be opened so that this room can be used as a grand café. Students can train the skills to run such a business. The working places of the mostly technically oriented prevocational contexts are positioned at the two sides of the $U$ of the ground floor. They can be opened 
to the outside as well so that they can be used as shops and be part of the shopping centre. So the ground floor is very flexible like a shopping centre. When the curriculum changes, the shops will change.

The first floor is positioned as an office. It is an open room with about one meter fifty high walls to get room for teams to work. Some parts have at the moment flexible walls to the ceiling so that working in a classroom situation will be possible. With ease these walls can disappear when the learning environment doesn't need them any more.

The building is an example of the bridging between learning, searching and working in the surroundings. Real life and all forms of activity take place on the ground floor. Reflection and study can take place on the first floor. Next to that not only adolescents will be in the building but also the whole community will get access.

\section{THE ROLE OF ICT}

ICT will lead to a different social and economic structure of society. As described above, the industrial society will have to be transformed into the information society. ICT is the tool for that like the steam engine has been it for the industrial society. That is in short the importance of ICT. So ICT is a facilitator. We think that in future society ICT will have the strongest impact on education.

To know about the role of a facilitator you have to know at first about the situation it will facilitate. That is one of the reasons why we described the changes in society in such an extensive way. We needed it to know more about the role of ICT in education. Let us recall what Copa said: "If knowledge is the centre of new society... It means that education is the leading branch of economy. How can we rethink that?"

When we apply this thesis on the role of ICT in education we have a good point saying that ICT will have the most impact on education. It makes also clear why the introduction of ICT in education has just started while it has already a role in other parts of society. Its role in education will be the most complex one and that means that the ICT apparatus must be developed enough. It will take a huge lot of bits to play a role in education. Just Internet gives us that huge lot of bits. It is obvious why it will take so many bits. The automation of processes of education has much to do with taking over actions of the brain by a machine. In industrial society these actions play a central role in organising society and they are much related to the way intelligence is defined. It has much to do with the education possibilities to become a citizen who is able to do his work in society as we described 
before. We think therefor that we are just at the start of the revolution generated by the introduction of ICT in education.

\section{$5.1 \quad$ ICT in society}

While we can only fantasise about the changes that will come, we are able to give some examples of the function of ICT in companies. The first automation wave strengthened the island structure of a company. It was organised from the inside to the outside. For every question the client had to go from one counter to another. This organisation structure was reinforced by the first automation wave. Every counter was automated separately. The cohesion within the company was reduced. So at first the organisation has to redefine itself so that ICT could support the integration. ICT can support companies for real only, if the organisation turns itself inside out. So by the redesigning organisations are not anymore reconstructed from the inside out (bureaucratically), but from outside in (as a network). The whole of the organisation becomes subservient to the existing and future client through any counter anywhere in the world. ICT makes it possible that the communication in the enterprise will speed up and get another interactive non-hierarchical approach. The organisation becomes demand-driven in stead of supply oriented. A good example is the way you get your money from a bank in the past and nowadays. ICT facilitates and accelerates this paradigm shift by its integrating possibilities.

Also skills needed by staff workers are changing. For example, in supermarkets adding is not a necessary skill anymore but has been automated. So whole production processes with all the skills needed by employees are now automated. When we speak about the new curriculum that enterprises need for their staff in information society and about the change from cognition abilities towards skills, it is just because of that. Many of the procedures that are organising society now will be taken over by ICT. And the brain damage people got by learning themselves all these procedures will probably for a big deal belong to the past.

\subsection{ICT in education}

The description is supporting the changes we foresee in education. At first the integration. We described the integration of the traditionally subjects in contexts. It may be clear that this complex process can be fixed by ICT. No more fifteen subjects (fifteen counters) with each its own (partly) automated educational materials, but integrated educational materials designed around the demand-driven contexts. ICT facilitates the production of these made-to-measure products. It makes education indeed demand- 
driven. "City Works" will become "Working with the Global Village" by the possibilities of Internet.

Next to that it gives a total new way of communication. We see that in the new sort of contact between teachers and students, between schools, etc. by e-mail, tele-learning and videoconferencing. These communication possibilities can be mixed with others. In education the process side (the learning process) is at least as important as the product side (achieving the curriculum). This certainly applies to these days as more and more attention is paid to the coaching of students, for which a good student monitoring system is a prerequisite. The tool used for this, what we call the SDRE-circle (See, Diagnose, Remediate, Evaluate, and da capo) is a wonderful aid. Similar ways of assessment are automated well with ICT. A sufficient database can monitor the student's entire learning process and interfere continually if the learned items do not stick. It gives the student its own Learners Information System (LIS). And we can use this tool also to get a Management Information System (MIS). Both can help to accelerate the learning process significantly. It is necessary, however, that students $\log$ in on the computer for all their central activities. So the new learning won't start anymore from books supported by computers, but it will start from the computer supported by books. Every student will have his "personal assistant", which will support his learning. This makes very clear the changing in the learning organisation. With the MIS it can support also the organisational changes of the schools, that mean the coaching and team role situation described before.

We think that the most important influence of ICT in education has to do with the curriculum. Many things we are learning at school nowadays are not necessary to learn any more. We are just at the start of thinking about these things but we think the upgrading of the intelligence level of society has to do with this. The spelling control of my computer program is an example of it. But the role of all procedures that we have in education will be questioned. They are until now necessary to become this citizen that can play its working role. When ICT will take it over it gives us time and opportunity to get to the real goal of education described by Howard Gardner. So ICT possibilities will question what we have to learn.

You can combine this all with other new possibilities of ICT. Ever since printing was invented an enormous acceleration of knowledge has taken place because the image language made by artists (in the churches) was replaced by textual language. The latter made knowledge accessible to large groups. Multimedia again allows an acceleration of knowledge. It is achieved by partly replacing text by image. With the aid of images it will be possible not only to learn faster, but also more thoroughly, because the very, not or only hard to express, unknown can be known through images. 


\subsection{The implementation}

We have already done quite a lot to implement the changes we want to introduce. The architecture of the building is the most important part of it. We introduced back-casting as management tool for changes. Back-casting is used in environmental policy. One has to describe at first the future situation. After that one uses the nearby future as a transition situation from today to the future. It means that the nearby future will not be a blow-up of today but really another situation that refers to the future.

As said before, we started to transform real life. From there we can use the possibilities of ICT. So next to the change in learning environment we are busy with the three other mentioned changes: the organization of the school, the role of the teacher and the student, and the curriculum. Next to that we are trying to use ICT to support the different changes.

\section{$5.4 \quad$ The internal process}

At first we will give you a description of the internal process in the school on the three subjects. The most important and the most difficult is the change in the curriculum. As we have seen there are two basics for contextorientation: "City Works"/ "Working with The Global Village" for pupils from 12-14 years, and prevocational subjects for pupils from 14-16 years. We have many choices of ourselves in the curriculum for the years 12-14. But the curriculum for 14-16 years has to lead to a national examination. There is a huge national discussion about the curriculum at the moment. We try to play a role on this subject but the outcome is still not clear. Because of that we have chosen in the school to start our transformation and to learn how to manage it by working on "City Works". The program is functioning in more schools in The Netherlands and it has governmental support. We started in one group in the first class (12-13 years) with two teachers. They made their own program for 4 hours a week. So in stead of fifteen subjects these pupils had sixteen subjects because parts of the other subjects were put in "City Works". We had good results with it, so we started last year with a new group in the second class; and more teachers are involved in it. In the meantime we started in the first class to digitise parts of the program as the first school in The Netherlands. At the moment we are busy to plan the transformation from "City Works" as extra subject into "City Works" as the only subject of the first class. In this new environment we are experimenting with the new role for teacher and student as well. All teachers of the school are participating in introducing ICT and Internet skills. As an ICT front school we have relatively much ICT-equipment. Searching and introducing good software is nowadays becoming more urgent. 
Next to and in co-ordination with it we are changing the learning organisation. We are diminishing the amount of teachers in a class. So they have to teach in different subjects. Duo-teaching has started. Two teachers are responsible for a double group while they help each other in their own learning process. We are busy to build a network organisation in the whole group of schools as well. So the directory of the whole group participates in all the changes we are managing. Like all other schools in The Netherlands we are busy to automate our management organisation so that we can communicate in a stronger way. We are also experimenting with these assessment programs leading to the so-called "personal assistant". So we are really doing a lot of work in the internal implementation of the design.

\section{$5.5 \quad$ The external process}

Maybe the external implementation is giving the most problems. In The Netherlands education is in permanent discussion these days. The design of the school plays a role in the discussion. And we are constantly busy to scale things up by starting new initiatives and taking part in others. The problem is that real changes are only possible when generally introduced and old thinking still has many roots in society. So the changing process has to get its time. It means that the coupling of the internal and external process is very complex. The ambition of the school is to be an example of new education. But the general organisation of the curriculum diminishes the possibility to be it. Co-operation is a central issue. Here we will mention only two forms of co-operation that we think are essential for us.

At first we are strongly related to the influential non-governmental organisation of principals in The Netherlands. As said before the management of the school plays an important role in school organisation. A national board of principals can give strong support. This board in The Netherlands is the organisation VVO. It is part of a European counterpart called ESHA and an international one called ICP. All these nongovernmental organisations will play a crucial role in the transitions made all over the world. Our school is closely related to the national board and has its relations with the international ones. It gives our school a more structural position in the country.

The second co-operation is a starting public private partnership in The Hague between the educational field, the local government and the international Telecom Company KPN. The partnership is meant to organise the participation of 13000 students in The Hague mobile linked to a virtual educational community. We think that this project will be the real start of the transformation. In our view a change between the public and private domain is essential for the forming of a knowledge society. 


\section{CONCLUSIONS}

As described in this paper we did a lot of thinking but we acted a lot as well. One will understand that other schools of Schoolgroup Esloo are changing as well. This performs a climate of changing all around our group of schools. We taste this climate nation-wide and the possibilities to work on our design wouldn't have been so big without this atmosphere. We have been in a lot of countries now and we have read a lot of relevant literature.. So we know that this atmosphere is world-wide. School managers are in a crucial position. The changes can't be introduced anymore in a hierarchical way far away from our schools. So school managers have to take their responsibility. National boards of principals like the VVO in the Netherlands will play a crucial role as initiators of the transformation process.

ICT has a lot to do with these transformations. But is no more than a tool. We have to rethink the learning process and the position of the learning process in the knowledge society at first. During and after the transformation process ICT will play its facilitating role. By acting this way we are able to give education its important position where it can give room at the realm of the truth, the beautiful and the good.

\section{REFERENCES}

Delors, J. (1996) Learning, the treasure within, Unesco, Paris.

Gardner, H. (1999) The disciplined mind, New York.

Kuhn, T. (1996) The structure of scientific revolutions

Maturana, H. and Varela, F. (1980) Biology of Cognition, in Autopoiesis and Cognition, edited by D. Reidel.

Toffler, A. (1980) The third wave, London.

\section{BIOGRAPHY}

Jaap Westbroek is chairman of the board of Schoolgroup Esloo and member of the VVO, the Dutch national board of principals in secondary education. He has studied biochemistry and was a teacher in biology, physics and chemistry. He wrote many articles about education in The Netherlands and is co-author of the Esloo-design. 